\title{
Adoption of mobile internet devices and services: a multinational study
}

\author{
Ravi S. Sharma* \\ Wee Kim Wee School of Communication and Information, \\ Nanyang Technological University, \\ 31 Nanyang Link, Singapore \\ E-mail: rsharma@pmail.ntu.edu.sg \\ *Corresponding author

\section{Eldon Y. Li} \\ Department of Management Information Systems, \\ College of Commerce, \\ National Chengchi University, \\ Taipei, Taiwan \\ E-mail: eli@nccu.edu.tw
}

\section{Rubie Govindraj}

The Walter Cronkite School of Journalism and Mass Communication, Arizona State University, 555 N. Central Ave., Suite \#302, Phoenix, AZ 85004, USA

E-mail: rubiegovin@gmail.com

\begin{abstract}
Despite the exponential growth in mobile subscription rates worldwide, research into the antecedents of mobile internet technology adoption behaviour has been sparse. This study attempts to fill that research lacunae. A device-service adoption model that is based on adaptive structuration theory and the perceived value paradigm is proposed and empirically tested with structural equation modelling (SEM) using data collected from five major markets, including Finland, Singapore, South Korea, Taiwan, and the USA. The study provides an explanation for the variance in the levels of adoption across the five markets. The findings do not entirely conform to those of prior studies. The results reveal that consumers' preferences in adopting mobile internet devices and services vary across markets according to adaption and value. The results also show the significant effects of income level on the adoption of mobile internet devices and services across these markets. Finally, theoretical and practical implications are discussed.
\end{abstract}

Keywords: mobile data services; mobile device; perceived value; adapted benefits; purchase intention; mobile services strategy.

Reference to this paper should be made as follows: Sharma, R.S., Li, E.Y. and Govindraj, R. (2014) 'Adoption of mobile internet devices and services: a multinational study', Int. J. Information Systems and Management, Vol. 1, Nos. 1/2, pp.60-82. 


\begin{abstract}
Biographical notes: Ravi S. Sharma is currently the Principal Investigator of the Special Interest Group on Interactive Digital Enterprises which is an NRF-funded project. He has been an Associate Professor at the Wee Kim Wee School of Communication and Information at the Nanyang Technological University since January 2004. He spent the previous ten years in industry as Asean Communications Industry Principal at IBM Global Services and Director of the Multimedia Competency Centre of Deutsche Telekom Asia. His teaching, consulting and research interests are in knowledge and digital economic strategies. He has published over 100 technical papers in leading journals, conferences, trade publications, and the broadcast media, as well as a research collection of papers on understanding the IDM marketplace.
\end{abstract}

Eldon Y. Li is the University Chair Professor at National Chengchi University in Taiwan. He was the Dean of College of Informatics and Director of Graduate Institute of Social Informatics at Yuan Ze University in Taiwan, and Professor and Coordinator of MIS Programme at the College of Business, California Polytechnic State University, San Luis Obispo, California, USA. He was a Professor and Founding Director of the Graduate Institute of Information Management at the National Chung Cheng University in Chia-Yi, Taiwan. He received his PhD from Texas Tech University in 1982. He has published over 200 papers in various topics related to innovation and technology management, human factors in information technology (IT), service science and technologies, strategic IT planning, and information systems management. $\mathrm{He}$ is the President of International Consortium for Electronic Business and Asia Pacific Decision Sciences Institute in 2007-2008.

Rubie Govindraj is a PhD student at The Walter Cronkite School of Journalism and Mass Communication, Arizona State University. Her research interests are in the areas of business models for online news organisations and the creative industries, as well as the political economy of new media. She was presented with the Second Industry Research Competition Award at the 2013 AEJMC Conference in Washington for a proposal that she submitted to the Council of Affiliates, AEJMC. She brings to her research more than 25 years of work experience as a broadcast journalist, media entrepreneur, and media educator.

\title{
1 Introduction
}

Mobile internet devices and services (MIDS) are characterised by devices, typically known as smart-phones, which have sophisticated input-output-processing-storage features and broadband connectivity. The devices allow both internet browsing and a range of intelligent applications which utilise location-detection, authentication and multi-tasking. Such MIDS offerings have become an inescapable part of our lives. Work, leisure and all forms of day-to-day activities increasingly depend on them. As a result, MIDS providers today offer a plethora of products and services enabling consumers to perform various forms of work and leisure tasks related to commercial transactions, networking and communication, information access, and content downloading (Garbacz and Thompson, 2007). This is an integral part of the era of ubiquity.

The extent of such diffusion of applications and services is evident from the staggering subscription rates worldwide (Hicks, 2010). The global mobile services subscription rate has approached four billion, and between 2007 and 2008 saw an increase of $23.2 \%$ (ITU, 2010). On average, 59 out of 100 people worldwide subscribed 
to mobile telecommunications. Finland, the leading mobile penetration market in Europe, had 7 million subscribers with a penetration rate of $128.76 \%$ by 2008 , while the USA had a penetration rate of $86.79 \%$ at this time. Mobile phone subscriptions in the Asia Pacific region had grown at a compound annual growth rate (CAGR) of nearly $33 \%$; greater than the world average of $31 \%$. Market leaders include South Korea with 46 million subscribers from a population of 48 million and Taiwan with a total of 25 million subscribers from its population of 23 million. With the mobile industry thriving with such rates, the inevitable question that researchers ask is: what will continue driving consumers today to adopt new mobile devices and services?

In a globalised telecommunications marketplace, there could be several, non-discriminant factors that determine consumers' decision to purchase mobile devices and services, ranging from those related to the consumers' own needs and preferences to the vendors' offerings and promotions. On the one hand, consumers today are sophisticated buyers, who come with expectations, the purchasing power to pay for those expectations, and who have access to information about their purchases; on the other hand, today's $3 \mathrm{G}$ technology, that integrates rich media, sensor-actuator technology, virtual environments and interactive computing in ambient systems, has the potential to offer consumers an unprecedented level of convenience and flexibility for living and working. It is against such a backdrop that this research is positioned.

The significant boom in the MIDS industry has attracted much scholarly interest across both the information systems as well as technology management disciplines over the past decade (c.f., Adams et al., 1992; Barnes and Scornavacca, 2004; Carlson et al., 1999; Davis, 1989; Dholakia et al., 2004; Kim et al., 2007; Lee et al., 2002; Venkatesh and Brown, 2001; Turel et al., 2007). Particularly, much work has been done in studying mobile services adoption across sectors (Kim and Han, 2009), markets (Mante, 2002), policies (Vrechopoulos et al., 2003), and business models (Massoud and Gupta, 2003)

However, there is still insufficient understanding as to what MIDS consumers want that could be applied across markets (globally) or customised to a given one. For example, why consumers switch from one brand to another, whether it is the device or its applications that drives adoption intent, has not been examined on a global scale sufficiently (cf., Barnes and Scornavacca, 2004; Garbacz and Thompson, 2007). The investigation reported in this paper is part of the Worldwide Mobile Data Services Survey comprising 15 countries including Australia, Canada, China, Denmark, Finland, Greece, Hong Kong, Hungary, Japan, Korea, Singapore, Spain, Sweden, Taiwan, and the USA. It is a modest attempt at filling that research lacunae and providing an explanation for the antecedents to mobile adoption intention globally as well as in specific markets.

The objectives of this research are to understand what global consumers want from MIDS and what factors contribute to the adoption and purchase intentions of MIDS in the era of convergence and globalisation. Is there a product-service schism in user adoption? Alternately, is the mobile device decoupled from the service it can offer when consumers consider value? Does adoption depend on a purpose of use or perceived benefit? Alternately, does it depend on the means or the ends? Is there a global trend in terms of the attributes desired? Alternately, are user adoption characteristics consistent across global markets?

Using data from Singapore, Finland, the USA, South Korea and Taiwan, this study examines the main antecedents of mobile technology adoption behaviour in these markets. All five markets are mature markets in the global telecommunications marketplace; so it would be interesting to study how far the antecedents to MIDS 
converge or diverge in these markets. Such insights will help MIDS providers in their branding and marketing decisions and policies in these markets. The next section reviews prior research in the adoption of technology in order to formulate a research framework.

\section{Background research}

Among the early empirical studies on technology diffusion, the technology acceptance model (TAM) of Davis (1989) postulated that the acceptance of a technical solution was mediated by Perceived Usefulness and Perceived Ease of Use. However, other researchers have found the TAM 'parsimonious' at best (Kim et al., 2007), claiming that the model is insufficient to account for user behaviour today. Unlike Davis's sample which comprised IS users of a single business organisation, today's global consumers subscribe to MIDS for their own personal use. When consumers buy mobile devices or subscribe to internet services on an individual pay-per-use basis, they will need to weigh in the relative gains against the relative costs. This change in potential adopters from being technology users to voluntary consumers has led researchers to examine the notion of 'perceived value' for the consumer (Zeithaml, 1988; Sweeney and Soutar, 2001; Venkatesh and Brown, 2001; Kim et al., 2007; Turel et al., 2007). For example, Zeithaml (1988) postulated perceived value as a salient determinant of consumer behaviour which is determined by the consumer's perceptions of the gains that are received. After discounting what is given in terms of costs and sacrifices, it determines the consumer's overall assessment of the utility of the product.

In another vein, Richardson (2007) theorised that as mobile communications technologies have become a ubiquitous part of life in the modern world, they have reached some intimacy with users due to their physical proximity and their engagement with multiple senses (e.g., hearing, vision, touch). This demands more somatic immersion (i.e., bodily functions rather than mental) from the user in terms of desired outcome. However, there is not a general consensus among researchers. Several other studies in the marketing and IS domains have empirically shown that perceived value is multi-dimensional and may be measured by a variety of attitudinal as well as behavioural instruments. For example, Sweeney and Soutar (2001) conceptualised perceived value as having four distinct value dimensions: performance/quality, emotional, value-for-money and social. Performance/quality value is a functional factor that captures the utility of the product. Emotional value is the utility derived from the affective feelings or affective states generated by the product. Value-for-money refers to the trade-off between benefits and costs involved in using the product. Social value is the enhancement of both self-image and relationships that will be achieved as a result of using the product. Venkatesh and Brown (2001), and later, Brown and Venkatesh (2005) further examined three similar evaluation criteria as key factors in determining the adoption intentions of mobile technology users. The first is the utilitarian value which relates to the effectiveness and efficiency resulting from the use of IS and is associated with functional values like quality and monetary value. The second is hedonic value which represents fun and pleasure derived from using the IS. The third is social value defined as the enhancement of the social image of the user through the use of the IS. In this paper, we consider these three sets of value as benefits. 


\section{Theoretical framework}

Traditionally, technology adoption research has favoured a sequential chain such as attitudes, beliefs, intentions and behaviour (c.f., Adams et al., 1992; Chang and Wildt, 1994; Chiu, 2005; Davis et al., 1992; Marco and Frenkel, 2000; Massoud and Gupta, 2003; Turel et al., 2007; Venkatesh and Davis, 2000). Continuing this tradition with the means-end chain theory, Chiu (2005), Gutman (1982), Reynolds and Gutman (1988), among others, have shown purchase intention as a cognitive process that consumers use in hierarchically linking concrete product attributes to abstract psycho-social consequences of the attributes. Applied to the context of this research, this implies that concrete attributes of MIDS would lead consumers to expect certain abstract benefits for themselves which will then lead them to concrete action in the decision to purchase and adopt MIDS.

An alternate theoretical lens for understanding MIDS adoption is through adaptive structuration theory (AST), first proposed as a sociological precept of structuration by Anthony Giddens (1984). This was applied to information technologies as AST in the pioneering work of DeSanctis and Poole (1994) and later, Orlikowski (2000). From an AST perspective, agents (i.e., MIDS users) and their social actions (i.e., purpose or benefit of MIDS) form 'the duality of structure' both of which are necessary in analysing the adoption of mobile technologies in terms of their twofold nature as medium and outcome. DeSanctis and Poole used Giddens' notion of 'modalities of structuration' to determine how social structures are appropriated into user purpose and how technology is used with respect to this 'spirit'. Orlikowski replaced DeSanctis and Poole's notion of 'embedded properties' (i.e., MIDS design attributes and features) for user enactment (i.e., MIDS adoption). Thus, in a sense, AST constructs a bi-directional means-end chain comprising attributes which are adapted by users for the perceived benefits and result in adoption.

Building on this, the value of MIDS is determined by both users' perceptions of benefits that accrue due to the use of MIDS as well the purpose for which such technologies are used. The classic perceived value paradigm (PVP) from behavioural decision sciences presumes that there exists a cognitive trade-off between perceived cost (quality of effort) and perceived benefits (quality of outcome) in decision-making process (Beach and Mitchell, 1978; Payne, 1982; Johnson and Payne, 1985). It posits that if consumers predict they could obtain more benefits from the usage of a product or service, they would consequently be more willing to pay for them and use them.

Marco and Frenkel (2000) suggest that product attributes refer not only to observable characteristics like colour, shape, size and weight, but also to intangible qualities like brand reputation and product image. They also classify some of these outcomes as functional and psychological benefits. Functional benefits are directly generated when users adopt the product, while psychological benefits are related to social outcomes and satisfactions (i.e., social image, better personal relation and self-advancement). This simple classification has been expanded in the IS and technology management literature. There is considerable agreement in the IS literature that technology benefit may be expressed as utilitarian, hedonic or social (Brown and Venkatesh, 2005; Heijden, 2004; Kim and Han, 2009; Sweeney and Soutar, 2001). Utilitarian benefits are those associated with functionalities of MIDS pertaining to commercial transactions, communications and content downloads; hedonic benefits are the pleasure and fun users experience when using MIDS; and social benefits include self-image and relationship enhancement 
consequences. Hence, perceived value, which is the net outcome that the consumer obtains after both benefits and costs (product price) are evaluated (Chang and Wildt, 1994; Chen and Dubinsky, 2003; Sweeney and Soutar, 2001; Zeithaml, 1988), determines the consumption action or decision to purchase. Other recent IS studies that have attempted to use the PVP in explaining mobile adoption behaviour include Kim et al. (2007) and later, Kim and Han (2009). Both studies have reported positive correlation between perceived value and the adoption intention of consumers.

Drawing on the above theoretical constructs, a research model for MIDS adoption drawing from the AST and the PVP is proposed. The model, shown in Figure 1, suggests a relationship between consumers' expectations of MIDS attributes and adaptations that result in perceived benefits. The model also holds income as a control variable, given the empirical evidence that people with different incomes may have differences in the costbenefit equilibrium.

Figure 1 Research model synthesised from prior theories

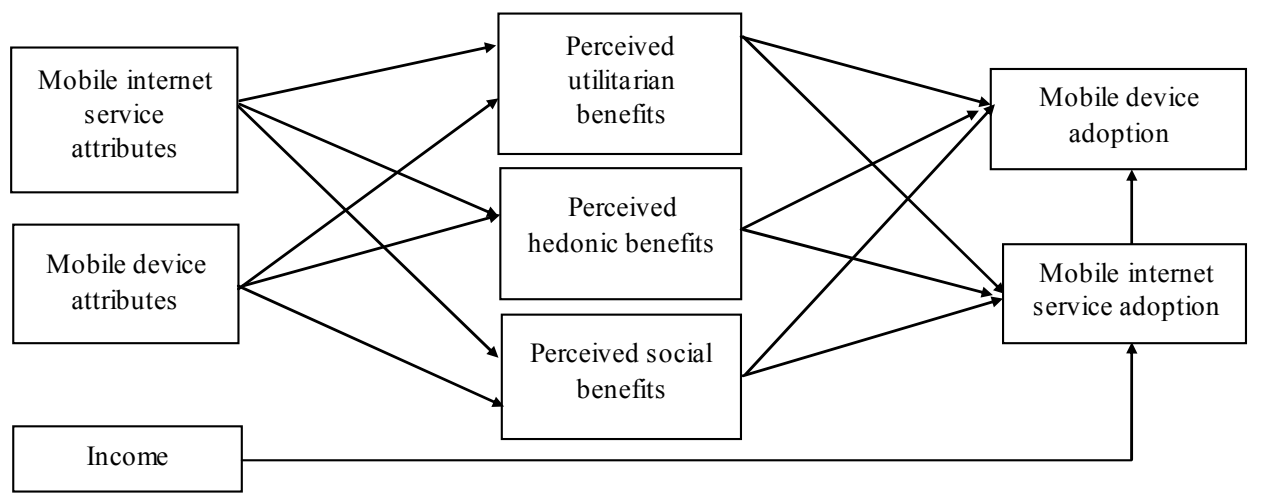

In this model, AST is used as a theoretic lens in order to examine consumers' decisions on what determined the adoption of new mobile devices and services. The model theorises three points on interest in this study. First, the natural association between consumers' expectations of MIDS attributes and the adoption of MIDS is taken into consideration. Second, the dual effects of expected attributes from mobile devices and mobile internet services on multiple dimensions of perceived benefits are examined. Third, the effect of the overall perceived value derived from the trade-off between benefits and costs gives the adoption intention of MIDS users. In the next section, two sets of hypotheses are derived from this model; one relating to perceived benefits and the other relating to willingness to pay.

\section{Research hypotheses}

It has been suggested in the literature that perceived product attributes lead to perceived product values (Reynolds and Gutman, 1988). By consuming expected mobile device and mobile internet service attributes, users derive satisfaction and benefits. Higher expectations of mobile product and internet service attributes lead to higher levels of satisfaction (Shi et al., 2009). Perceived values are multi-dimensional and include 
utilitarian, hedonic and social benefits (Brown and Venkatesh, 2005; Kim et al., 2007; Kim and Han, 2009). Thus, we derive the following hypotheses:

H1a Expected mobile internet services attributes are positively related to perceived benefits of obtaining greater utility.

H1b Expected mobile internet services attributes are positively related to perceived benefits of obtaining greater hedonic benefits.

H1c Expected mobile internet services attributes are positively related to perceived benefits of enhancement of social image and relationships.

H1d Expected mobile device attributes are positively related to perceived benefits of obtaining greater utility.

H1e Expected mobile device attributes are positively related to perceived benefits of obtaining greater hedonic benefits.

H1f Expected mobile device attributes are positively related to perceived benefits of enhancement of social image and relationships.

It has been observed that mobile consumers will balance their perceived benefits and perceived costs before purchasing products and services (c.f., Barnes and Scornavacca, 2004; Bohlin et al., 2004). In this study, what consumers are willing to pay for new mobile devices and mobile internet services is weighed against their perception of the benefits that accrue from MIDS adoption. Therefore, a positive association between dimensional benefits and willingness to pay for mobile devices and mobile internet services is hypothesised.

H2a Greater perceived benefits in terms of utility lead to greater willingness to pay for mobile devices.

$\mathrm{H} 2 \mathrm{~b}$ Greater perceived benefits in terms of hedonic benefits lead to greater willingness to pay for mobile devices.

$\mathrm{H} 2 \mathrm{c}$ Greater perceived benefits in terms of enhancement of social image and relationships lead to greater willingness to pay for mobile devices.

$\mathrm{H} 2 \mathrm{~d}$ Greater perceived benefits in terms of utility lead to greater willingness to pay for mobile internet services.

H2e Greater perceived benefits in terms of hedonic benefits lead to greater willingness to pay for mobile internet services.

$\mathrm{H} 2 \mathrm{f}$ Greater perceived benefits in terms of enhancement of social image and relationships lead to greater willingness to pay for mobile internet services.

\section{Research method}

\subsection{Sample}

We used as the sample for this study the respondents from five different countries: Finland, Korea, Singapore, Taiwan and the USA. We used both paper-and-pen and web- 
enabled versions of the data collection instrument to collect data in Singapore for the pilot run before collecting data from the other countries. The online questionnaire adopted from Sharma and Felix (2008) was posted during 2009-2010 period using a professional version of the SurveyMonkey tool. Only participants with prior MIDS experience were asked to participate, and their user profiles were subsequently used as a check of their internet experience. After the pilot run, more data were collected in Finland, the USA, Korea and Taiwan with paper-and-pen questionnaires and almost a full response rate was achieved in each country, perhaps due to the attraction of receiving pre-paid mobile services cards. After removing the unusable samples, the demographic profile of respondents is shown in Table A1 of the Appendix.

\subsection{Questionnaire}

To enforce rigor in the design and collection, research collaborators from the participating institutes worked closely in designing the questionnaire and conducting the survey. Questions were designed to obtain respondents' attitudes towards MIDS attributes (e.g., device features, service offering, bundling), perceived benefits (e.g., utility, hedonic, social) and adoption intentions (e.g., usage, willingness to pay). These were measured on five-point Likert scales. More specifically, expected device attributes included questions on user-friendliness, simple-intuitive navigation, easy to learn, customisation features, battery life, size-weight, memory capacity and attractive design. Expected service attributes included communication features, data-oriented features, functionality for games, multi-tasking, fast access to mobile data services, and enjoyable content. Perceived benefits of utility, hedonic and social services were measured by asking respondents to rank the importance of various MIDS attributes such as:

1 access to information such as news, weather-traffic reports, corporate electronic mail and calendars

2 access to entertainment such as music, video, games and sports

3 access to personal and social networks that support relationships.

Willingness to pay for mobile devices was obtained by asking respondents their threshold for costs:

1 under $\mathrm{S} \$ 50$

$2 \mathrm{~S} \$ 51-\mathrm{S} \$ 100$

$3 \mathrm{~S} \$ 101-\mathrm{S} \$ 300$

$4 \quad \mathrm{~S} \$ 301-\mathrm{S} \$ 500$

5 over S\$500, where S\$ represents Singapore dollars.

Willingness to pay for MIDS was obtained by asking respondents their threshold for costs:

$1 \mathrm{~S} \$ 0-\mathrm{S} \$ 9$

$2 \mathrm{~S} \$ 10-\mathrm{S} \$ 29$

$3 \mathrm{~S} \$ 20-\mathrm{S} \$ 39$ 
$4 \quad \mathrm{~S} \$ 40-\mathrm{S} \$ 59$

5 above $\mathrm{S} \$ 60$.

Usage was captured by asking respondents to report their actual weekly average number of hours spent on basic voice-text and MIDS. Internal consistency and reliability was observed by building in at least three different questions aimed at assessing similar outcomes (Gefen et al., 2011). The validity and reliability of the data-collection instrument were pre-tested through a pilot run conducted with the Singapore data-set.

\subsection{Pilot test and results}

Generally, the data collection and analysis procedures followed the guidelines suggested by Gefen et al. (2011). Prior to using data from the four other selected markets for this study, a pilot test was conducted in Singapore to ascertain that the usability of key variables and the design of the instrument for the larger study were stable and acceptable. At the pre-test stage, responses were first collected through a pen-based questionnaire that was completed by mobile users in customer service centres (tele-shops) of a major mobile service provider.

After formatting and wording changes to the questionnaire, two equivalent forms of the survey were then implemented in order to reduce common method bias (Gefen et al., 2011). The paper-and-pen version was administered in the tele-shops while the online version of the survey instrument was disseminated via e-mail from April to June, 2009. As an incentive to participate, respondents were offered a $1 \%$ chance of winning by lottery (i.e., one selected by a random number generator for every 100 respondents) a Blackberry Curve sponsored by Research in Motion Asia Pacific.

A total of 527 fully completed questionnaires were collected. Given the research object of investigating MIDS adoption, 317 participants who had sufficient post-paid MIDS usage of at least a year were included in the subsequent data analysis (Shi et al., 2010). This was to avoid subsequent issues with missing data and non-response bias. As well, elimination of non-MIDS users allowed a deep analysis of the appropriate population of interest. Gefen et al. (2011) have suggested a minimum sample size of at least 200 and above the number that will give a statistical power of $80 \%$. For both the pilot as well as subsequent data analysis, the sample size was deemed sufficient to cover the number of observed variables and give the required power for the statistical hypotheses testing.

The hybrid research model comprising the key factors of perceived attributes, perceived benefits, perceived costs and adoption intention, was tested with structural equation modelling (SEM) using the Singapore data set. As stated in the earlier section, a total of 12 hypotheses $\left(\mathrm{H} 1_{\mathrm{a}-\mathrm{f}}\right.$ and $\left.\mathrm{H} 2_{\mathrm{a}-\mathrm{f}}\right)$ were tested.

The path analysis technique using AMOS 7.0 with maximum-likelihood method was performed to examine the hypothesised relationships among the exploratory constructs. The resulting model fit the data reasonably well from an empirical point of view: $\chi^{2}(\mathrm{df}=7, \mathrm{n}=304)=11.05, \mathrm{p}=0.14 ; \mathrm{CMIN} / \mathrm{DF}=1.58 ; \mathrm{CFI}=0.99 ;$ RMSEA $=0.04$. Cronbach's alpha scores ranged from 0.77 to 0.96 . Table A3 in the Appendix shows the observed covariance-variance matrix with regards to each factor, which identifies total effect on the endogenous variables. Two observations may be made at this point. With respect to perceived benefits, only expected mobile device attributes $(\beta=1.01, t=3.84)$ 
are significantly associated with perceived benefits for entertainment. Whereas, expected mobile services attributes are significantly associated with users' perceived utility ( $\beta=0.57, t=2.19)$, hedonic $(\beta=-0.79, t=-2.75)$ and social $(\beta=0.63, t=2.35)$ benefits respectively (although perceived hedonic benefits are negatively correlated). However, it is noteworthy that the three types of perceived benefits (utilitarian, hedonic, social) and income, together explain $14.3 \%$ of variance in mobile device purchase intention. More specifically, of the potential determinants of mobile device purchase intention, income ( $\beta=0.34, t=6.37)$ is the key factor. The perceived hedonic benefits $(\beta=0.10, t=1.78)$ also significantly affects a user's mobile device purchase intention, although the other two dimensions are not significant. Generally, the pilot test results provided a level of confidence for applying the statistical techniques outlined above to the global data set.

\subsection{Statistical data analyses for five markets}

For the global study, we collected in total 4,599 responded questionnaires in 2010. Among them, only 429 valid responses were selected out of 746 from Finland, 840 out of 1,077 responses from Korea, 561 out of 1,106 from the USA, 1,037 out of 1,143 from Taiwan, besides 317 out of 527 from Singapore. For the reasons outlined in the pilot test, the rejected responses were found to be unusable for statistical analysis since the respondents were not MIDS uses. Table A1 shows the demographics of the respondents from the five selected countries. The respondents are between the ages 18 to 49 years. The ratio of males to females varied from country to country but could be considered representative for the lack of any noticeable skew. The educational levels ranged from Primary School level to postgraduate level, while income varied from below $\$ \$ 24,000$ to above $\mathrm{S} \$ 100,000$.

As this study is exploratory in nature, it would make sense, according to Gefen et al. (2011), to use the path analysis option of structured equation modelling. In their view, SEM is the method of choice in analysing path diagrams involving latent variables (such as perceived benefits in this study) with multiple indicators. Once again the key variables were: expected mobile device attributes, expected service attributes, perceived utility, hedonic and social benefits, purchase intention and adoption of mobile devices and services. Income served as a control variable. AMOS 7.0 with the maximum-likelihood method was hence used. Table A2 in the Appendix shows descriptive statistics for each construct of the research model. Recall that mean values refer to the 5-point Likert scales and standard deviations refer to the dispersion of attitudes and opinions on the part of respondents.

\section{Analysis of global results}

It is apparent that the Path Analysis model fits the data reasonably well from an empirical point of view: $\chi^{2}(d f=25, n=2,908)=32.76, p=0.14 ; \mathrm{CMIN} / \mathrm{DF}=1.31$; CFI $=0.99$; RMSEA $=0.01$. Table A3 in the Appendix shows the outcomes of both direct and indirect effects in this study. In particular, the coefficients and $t$ values identify the associations between independent and dependent variables. For simplicity, Table 1 summarises results of each hypothesis tested. 
Table 1 Hypotheses testing using SEM

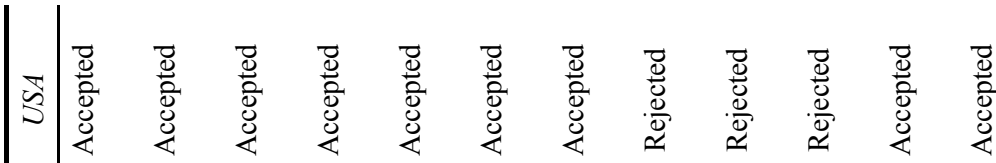

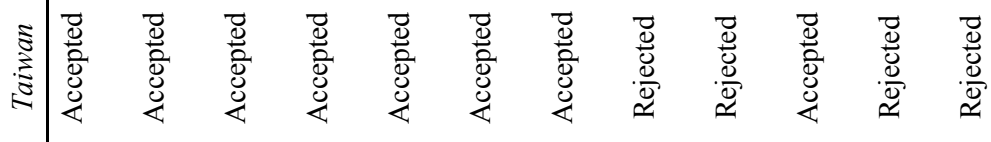

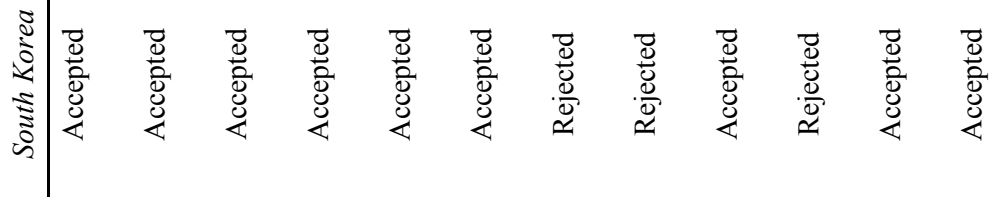

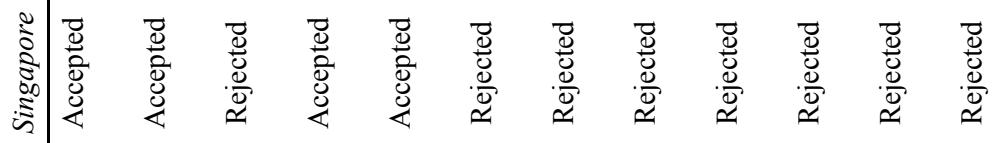

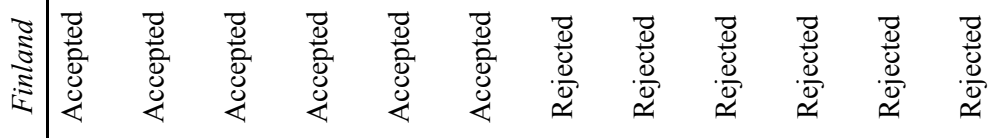

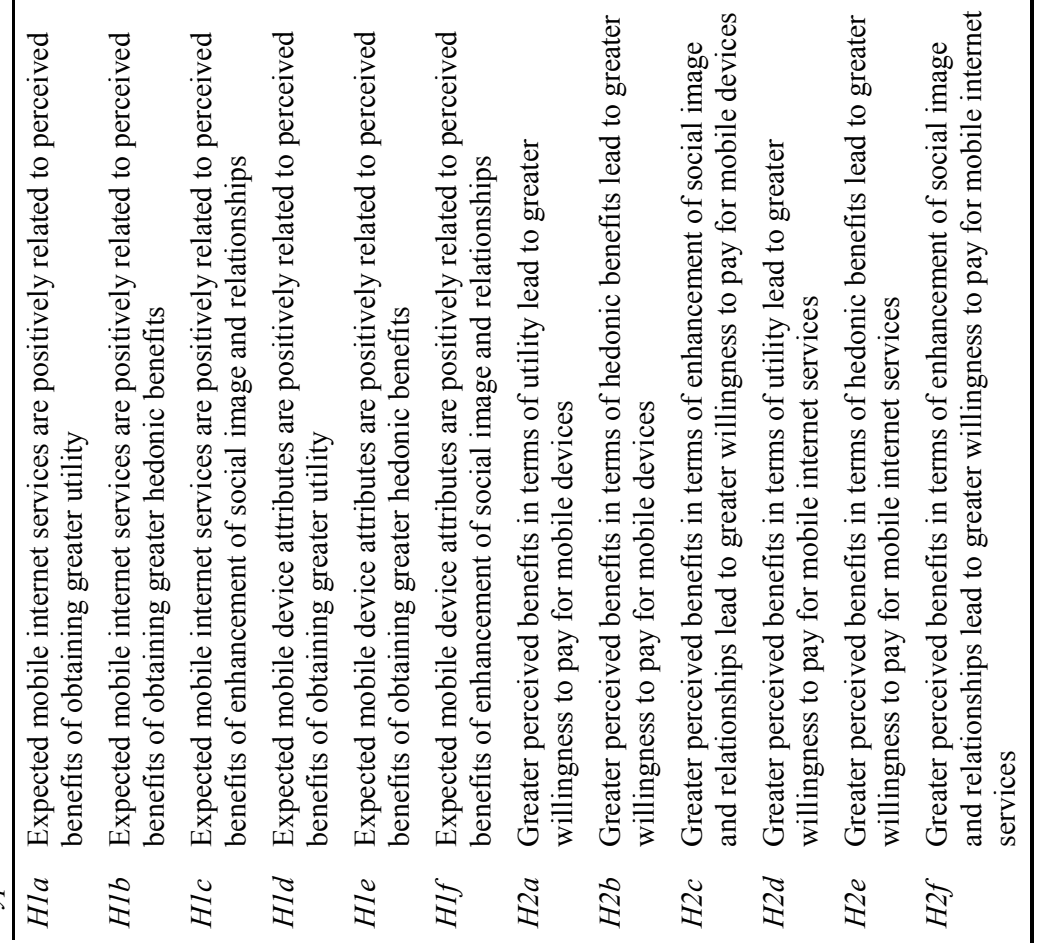


From Table 1, it is apparent that the first six hypotheses, showing the association between mobile device and service attributes and perceived utilitarian, hedonic and social benefits, have all been accepted (with the exception of $\mathrm{H} 1_{c}$ and $\mathrm{H}_{\mathrm{f}}$ in the pilot test which refer to social benefits). It can be concluded that the four major markets mostly accept that 'bundled' MIDS attributes create utilitarian, hedonic and social benefits for consumers. What is interesting, however, is that the second set of 6 hypotheses $\left(\mathrm{H} 2_{\mathrm{a}-\mathrm{f}}\right)$ showing the association between perceived utilitarian, hedonic and social benefits and adoption received mixed responses for Korea, the USA and Taiwan, and outright rejection by Finland. Another interesting finding is Finland's rejection of all 6 hypotheses that perceived utilitarian, hedonic and social benefits will influence adoption intention of MDIS - both devices and services. A market-by-market discussion follows in the sub-sections below.

\subsection{Finland}

The findings of SEM suggest that Finns expect to derive utilitarian, hedonic and social benefits for purchasing and consuming MIDS. Furthermore, they positively associate the attributes of mobile devices to their perceived utilitarian and hedonic benefits. Surprisingly, their willingness to pay for MIDS is not determined by any of the three perceived benefits, but by their expectations of service attributes $(\beta=0.33, t=6.64)$ and device attributes $(\beta=0.11, t=1.93)$. In addition, Finns who have higher incomes tend to consider perceived hedonic benefits as less significant than the other benefits.

\subsection{South Korea}

In South Korea, consumers' expectations of MIDS attributes significantly relate to their perceived benefits. Moreover, income does not significantly affect their perceived hedonic benefits. Additionally, their perceived hedonic benefits $(\beta=0.73, t=2.01)$ and social benefits $(\beta=0.74, t=2.03)$ together determine their willingness to pay for MIDS. But their intention to pay for new mobile devices merely depends on their perceived social benefits $(\beta=-0.07, t=-1.98)$. Korean consumers' expectations of device attributes influence their willingness to pay for both mobile devices $(\beta=0.28, t=8.14)$ and services $(\beta=0.15, t=3.94)$. But their expectations of mobile service attributes do not indicate any significant influence on their willingness to pay for MIDS.

\subsection{USA}

The consumption behaviour of consumers in the USA is similar to that of the Koreans, in that their expectations of bundled MIDS attributes significantly influence their perceived utilitarian, hedonic and social benefits. Moreover, like the Finns, Americans with higher incomes tend to have lower expectations of hedonic benefits. Furthermore, their willingness to spend on new mobile services is associated with their perceived hedonic and social benefits while their willingness to pay for new devices is determined by the perceived utilitarian benefits. In addition, income $(\beta=0.16, t=3.88)$ has a restraining influence on how much Americans will spend on a new mobile phone. Lastly, the expected mobile device attributes $(\beta=0.21, t=4.58)$ positively affect consumers' willingness to pay for a new mobile phone. 


\subsection{Taiwan}

In the case of Taiwan, consumers' expectations of product attributes are significantly associated with perceived benefits. However, in contrast to the Finns, Koreans and Americans, the Taiwanese care more about the utilitarian benefits that they can obtain when deciding on whether they will spend on MIDS. Moreover, income again serves as a critical factor in the purchase of new mobile devices and services. Furthermore, expected mobile device attributes $(\beta=0.22, t=7.09)$ and service attributes $(\beta=0.10, t=2.69)$ influence the willingness to pay for MIDS.

\subsection{Singapore}

In Singapore, MIDS attributes are not significantly associated with perceived social benefits, but are positively associated with utilitarian and hedonic benefits. Like the Finns and Americans, Singaporeans with high incomes do not have much interest in perceived hedonic benefits. Interestingly, Singaporeans' purchase intentions depend only on their income and no other factors. Like the Finns, none of the perceived utilitarian, hedonic or social benefits influence their purchase decisions.

\section{Discussion}

The empirical observations obtained in the previous section are tabulated in Table 2 for a more qualitative discussion. Though there are market differences, it is clear that MIDS users adapt attributes to suit their purpose in terms of generating the desired benefits. As well, though there were differences in the benefits that were sought from mobile devices and services, global consumers tended to bundle the attributes in deciding on adoption.

Clearly, the Finns, like Singaporeans but unlike Koreans, Taiwanese and Americans, show indifference to perceived utilitarian, hedonic and social benefits when making MIDS adoption decisions. Perceived benefits apparently do not influence their adoption decisions. They also seem ready to pay once they understand the product attributes. Income is not perceived as a determining factor for Finns. A possible explanation for such adoption behaviour could be that MIDS are necessities of daily life. As Puro (2002) concluded, Finland reached the highest per capita mobile penetration rate worldwide at the beginning of the year 2000 and such high penetration rates were significantly due to the prevalent influence of their environment. With sufficient knowledge about mobile products and a mature market, Finns focus on their personal initial needs and make sensible decisions without paying too much attention to the vendor-touted benefits for MIDS. As almost $70 \%$ of Finnish respondents in this research belong to 18-34 age group and nearly $60 \%$ of them earn less than $\$ \$ 5,000$ per month, catering advanced technology and better services especially to young consumers with low or middle incomes could be a sound way of growing market share in Finland.

Mobile consumers in the USA, Taiwan and Korea share some behavioural characteristics as they are pragmatic when considering the purchase of new mobile devices and services. Not only do they pay attention to the value or cost-benefit paradigm (questioning the perceived benefits they will obtain and the cost of enjoying such benefits), but also to the economic constraint of their incomes. Although American, Taiwanese and Korean consumers express the need to balance their perceived benefits 
and resulting costs, they focus on different issues. For instance, Koreans and Americans tend to be more concerned about the hedonic and social benefits arising from MIDS adoption. Taiwanese, however, place a premium on the perceived utilitarian benefits they will enjoy by adopting MIDS. With respect to the purchase of new mobile devices, Americans and Taiwanese look for utilitarian features while Koreans prefer social benefits.

Table 2 Summary of findings and corresponding strategies

\begin{tabular}{|c|c|c|}
\hline Market & Findings & Strategies \\
\hline Finland & $\begin{array}{l}\text { - Appreciate both device and service attributes } \\
\text { for their utilitarian, hedonic and social benefits } \\
\text { - Willingness to pay for mobile services depends } \\
\text { on mobile device as well as service attributes } \\
\text { rather than the perceive benefits } \\
\text { - Consumers with higher incomes tend to care } \\
\text { less for the perceived hedonic benefits. }\end{array}$ & $\begin{array}{l}\text { Given the sophisticated } \\
\text { market, advanced } \\
\text { technology and better } \\
\text { services may help service } \\
\text { providers gain market share. }\end{array}$ \\
\hline USA & $\begin{array}{l}\text { - Higher income earners tend to place less } \\
\text { importance on hedonic benefits } \\
\text { - Willingness to spend on MIDS is associated } \\
\text { with their perceived hedonic and social benefits } \\
\text { - Willingness to pay for new mobile device is } \\
\text { determined by the perceived utilitarian benefits }\end{array}$ & $\begin{array}{l}\text { Given such a demanding or } \\
\text { discerning market, service } \\
\text { providers should pay } \\
\text { attention to both product } \\
\text { quality as well as service } \\
\text { costs. They need to deliver } \\
\text { the most 'bang for the buck' } \\
\text { in the cost-benefit } \\
\text { equilibrium. }\end{array}$ \\
\hline South Korea & $\begin{array}{l}\text { - Appreciate both device and service attributes } \\
\text { for their utilitarian, hedonic and social benefits } \\
\text { - Perceptions of hedonic and social benefits of } \\
\text { adopting MIDS play a role in the final purchase } \\
\text { decision } \\
\text { - Perceptions of social benefits of mobile phone } \\
\text { appear to be a significant factor } \\
\text { - Income did not have any impact on purchase }\end{array}$ & $\begin{array}{l}\text { The most sophisticated and } \\
\text { demanding market, Koreans } \\
\text { are aware of the risk of } \\
\text { market failure for untested } \\
\text { products and innovation. } \\
\text { Even the famed Japanese do } \\
\text { not have significant market } \\
\text { presence in the Korea. }\end{array}$ \\
\hline Taiwan & $\begin{array}{l}\text { - Preference for utilitarian benefits that they can } \\
\text { obtain when deciding on spending on MIDS } \\
\text { and particularly, devices. }\end{array}$ & $\begin{array}{l}\text { A cost conscious market } \\
\text { which can be persuaded with } \\
\text { campaigns that inform } \\
\text { consumers of hedonic and } \\
\text { social MIDS. }\end{array}$ \\
\hline Singapore & $\begin{array}{l}\text { - Indifferent about what benefits they may obtain } \\
\text { when purchasing mobile devices and services } \\
\text { - Willingness to pay depends fully on purchasing } \\
\text { power and hence income }\end{array}$ & $\begin{array}{l}\text { Promotion strategies such as } \\
\text { trial offers, introductory } \\
\text { pricing and product bundling } \\
\text { may be the means of gaining } \\
\text { early adopters. }\end{array}$ \\
\hline
\end{tabular}

Such differences in adoption intention may be due to differences in cultural beliefs, social norms and technology adoption. According to Lee et al. (2002), with the highly developed MIDS landscape in Korea, it is convenient for Koreans to use MIDS like mobile banking, social networking with friends or watching mobile TV when commuting. Moreover, there is a relative shortage of fixed broadband capacity in rural Korea and the popularity of mobile devices can thus effectively alleviate such a digital 
divide. The characteristics of mobile devices also fit the Korean fashion culture in terms of communication and image. These factors combined explain why perceived hedonic and social benefits are important to Korean MIDS users. The lack of a positive relation between Koreans' willingness to spend on new mobile devices and their perceived social benefits is an anomaly that calls for further investigation.

Although there is a relatively uneven MIDS infrastructure across the USA as compared to Korea or Finland, Mante (2002) suggested that Americans are more responsive to being reachable by friends. Thus American perception of social benefits is significantly associated with their willingness to pay for MIDS. Moreover, the findings of this study are consistent with those in Katz et al. (2003) on the development of the rapid spread of MIDS in the USA. Americans have begun to show an interest in the hedonic and social benefits that MIDS can generate.

For the Taiwanese, utilitarian benefits are a priority when purchasing MIDS. One possible reason for this could be that the relatively conservative Taiwanese mobile market has not accepted MIDS for hedonic and social functions as yet.

\section{Conclusions and recommendations}

From a theoretical point of view, this research has served to broaden an understanding of the factors influencing mobile technology adoption. The study was conducted to fill the research lacunae that required greater in-depth and customer-oriented investigation into mobile technology adoption. The main theoretical contribution of this study is the hybridisation of AST and PVP in order to develop a model for MIDS adoption and tested them across five different markets. Several researchers have used the PVP (Kim et al., 2007; Turel et al., 2007; Sweeney and Soutar, 2001; Venkatesh and Brown, 2001; Zeithaml, 1988) to account for consumer behaviour with regard to adoption intentions. But the model proposed in this paper argues that the action of agents as well as the prevailing social structure are both necessary to explain and predict technology adoption.

Reynolds and Gutman (1988) postulated that the design attributes of a product can lead to perceptions of values and eventually user actions (adoption). This causal transition from attributes to values to adoption was not entirely observed in our findings. Furthermore, Sweeney and Soutar (2001), Venkatesh and Brown (2001), and Kim et al. (2007) have empirically shown that perceived value fully mediates the effects on consumers' beliefs about purchase intentions. But again, the findings of the present study do not fully corroborate these previous studies. Global adoption patterns for MIDS seem to deviate from other information technologies. While consumers accept that bundled MIDS attributes offer them utilitarian, hedonic and social benefits, results of the worldwide study so far indicate that the link between perceived benefits and adoption is mixed. In fact some participants in our study have categorically rejected that any of the three perceived benefits will influence their decision to purchase MIDS. This makes the perceived utilitarian, hedonic and social values weak antecedents in some countries. In fact income is a stronger antecedent in the markets which were studies. Further investigation of the relationship between consumers' motivations and their impact on technology adoption is needed, perhaps with longitudinal data.

This study however provides practical implications for the marketing strategies of MIDS service providers. We conclude from our investigation that perceived benefits and purchase intentions vary significantly across markets. There is no reason to believe that 
globalisation has forged a common consumer profile in the MIDS marketplace. As summarised in Figure 2, specific strategies in individual markets should be based on the finding that users will have different requirements and expectations of MIDS and will require distinctive functionalities. However, we may conjecture that industry growth strategies in terms of core features and characteristics may be shared across markets. On the basis of market maturity and network reach, the success of such strategies will also depend on factors such as infrastructure, consumer sophistication and joint efforts to grow the market among content providers, distributors and other players.

Figure 2 A general framework for MIDS adoption (see online version for colours)

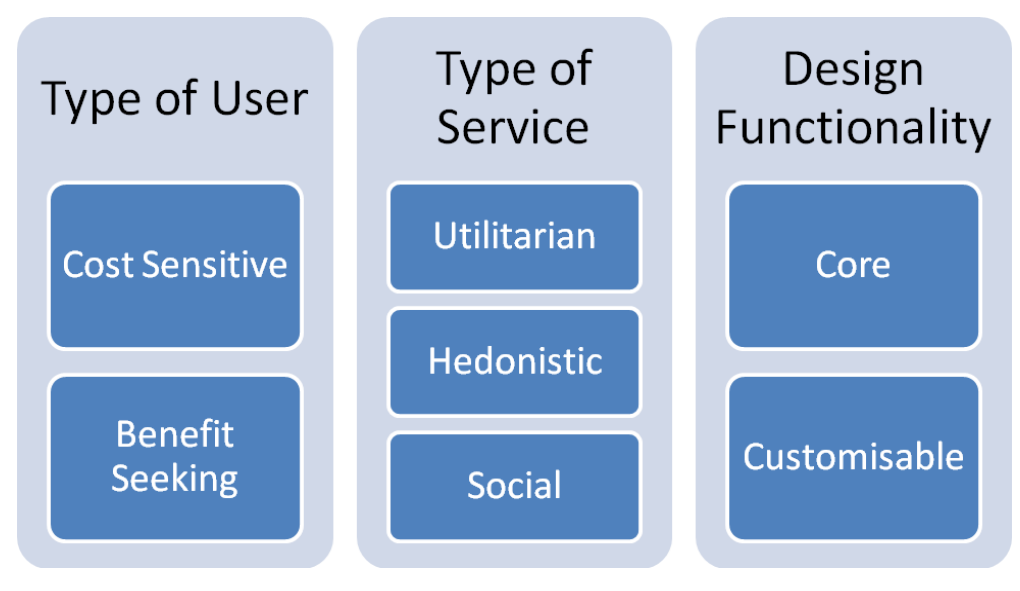

Figure 2 conceptualises this finding into three dimensions: type of user, type of mobile service and design functionality. It is clearly discernible from the five markets investigated that users are of two types: cost-sensitive and benefits-seeking. The type of user poses an important strategic choice from service providers when they pitch a service to a particular market and segment. The type of service - utilitarian, hedonistic or social - provides the value proposition for market entry as well as growth. Finally, the interaction between the above-mentioned dimensions leads to design choices on what features could be core functionalities that would appeal to a cross-section of global markets and what need to be customised to a given market. It would not make sense to take a 'cookie cutter' approach to package or bundle devices and applications.

While this study offers global observations for the adoption intention of MIDS, some limitations to the generalisation made in this study may be observed. First, there is an urban bias in the data collected: in the US, data was collected mainly from the Los Angeles County; Korean data came from Seoul; and Singapore is an urban city state. The results generated from such geographic areas may not be generalisable to a global MIDS market. An international study that examines the mature-emerging market divide as well as the urban-rural consumer divide will address this limitation.

Future research could also include value measures for hedonic, utilitarian and social benefits by examining the cognitive processes of each entirely. Finally, in addition to studying new markets, a future study could also derive a longitudinal chain which could track the changes of customer's perceptions of expected MIDS attributes, perceived benefits, realised values and willingness to pay. It is hoped that this paper, the first that reports the findings of a subset of the WMDSS, is a path in this direction. 


\section{Acknowledgements}

The research described in this paper (including the Singapore component of the Worldwide Mobile Data Survey) is part of the ongoing activities of the Special Interest Group on Interactive Digital Enterprise (SIGIDE) and funded by the National Research Foundation of Singapore. Many thanks are due to Alyssa Lee and Kristy Shi for help with the data collection and analysis. The authors are grateful to Elizabeth Fife and the WMDSS consortium for the collegiate sharing of datasets and findings.

\section{References}

Adams, D.A., Nelson, R.R. and Todd, P.A. (1992) 'Perceived usefulness, ease of use, and usage of information technology: a replication', MIS Quarterly, Vol. 16, No. 2, pp.227-247.

Barnes, S. and Scornavacca, E. (2004) 'Mobile marketing: the role of permission and acceptance', International Journal of Mobile Communication, Vol. 2, No. 2, pp.128-139.

Beach, L. and Mitchell, T. (1978) 'A contingency model for the selection of decision strategies', Academy of Management Review, Vol. 3, No. 3, pp.439-449.

Bohlin, E., Bjorkdahl, J., Lindmark, S. and Burgelman, J. (2004) 'Strategies for making mobile communications work for europe: implications from a comparative study', Info, Vol. 6, No. 6, pp.345-347.

Brown, S.A. and Venkatesh, V. (2005) 'Model of adoption in households: a baseline model test and extension incorporating household life cycle', MIS Quarterly, Vol. 29, No. 3, pp.399-426.

Carlson, P.J., Kahn, B.K. and Rowe, F. (1999) 'Organisational impacts of new communication technology: a comparison of cellular phone adoption in France and the United States', Journal of Global Information Management, Vol. 7, No. 3, pp.19-29.

Chang, T. and Wildt, R.A. (1994) 'Price, product information, and purchase intention: an empirical study', Journal of the Academy of Marketing Science, Vol. 22, No. 1, pp.16-27.

Chen, Z. and Dubinsky, A.J. (2003) 'A conceptual model of perceived customer value in e-commerce: a preliminary investigation', Psychology and Marketing, Vol. 20, No. 8, pp.323-347.

Chiu, C.M. (2005) 'Applying means-end chain theory to eliciting system requirements and understanding users perceptual orientations', Information and Management, Vol. 42, No. 3, pp.455-468.

Davis, F.D. (1989) 'Perceived usefulness, perceived ease of use, and user acceptance of information technology', MIS Quarterly, Vol. 13, No. 3, pp.319-339.

Davis, F.D., Bagozzi, R.P. and Warshaw, P.R. (1992) 'Extrinsic and intrinsic motivation to use computers in workplace', Journal of Applied and Social Psychology, Vol. 22, No. 14, pp.1111-1132.

DeSanctis, G. and Poole, M.S. (1994) 'Capturing the complexity in advanced technology use: adaptive structuration theory', Organization Science, Vol. 5, No. 2, pp.121-147.

Dholakia, N., Dholakia, R., Lehrer, M. and Kshetri, N. (2004) 'Global heterogeneity in the emerging global m-commerce landscape', in Shi, N. (Ed.): Wireless Communications and Mobile Commerce, pp.1-22, Idea Group Publishing, Singapore and Hershey PA.

Garbacz, C. and Thompson, H. (2007) 'Demand for telecommunication services in developing countries', Telecommunications Policy, Vol. 31, No. 5, pp.276-289.

Gefen, K., Rigdon, E.E. and Straub, D.W., (2011) 'Editor's comments: an update and extension to SEM guidelines for administrative and social science research', MIS Quarterly, Vol. 35, No. 2, pp.iii-xiv.

Giddens, A. (1984) The Constitution of Society: Introduction of the Theory of Structuration, University of California Press, Berkeley. 
Gutman, J. (1982) 'A means-end chain model based on consumer categorization processes', Journal of Marketing, Vol. 46, No. 2, pp.60-72.

Heijden, V.D. (2004) 'User acceptance of hedonic IS', Management Information Systems Quarterly, Vol. 28, No. 4, pp.695-704.

Hicks, R. (2010) 'Can mobiles close the digital divide?', Future Gov., Vol. 7, No. 1, pp.66-68.

ITU (2010) The World in 2010: ICT Facts and Figures (The Rise of $3 G$ ), International Telecommunications Union, Geneva, Switzerland [online] http://www.itu.int/ITU-D/ict/facts/2011/material/ICTFactsFigures2010.pdf (accessed 6 October 2012).

Johnson, E. and Payne, J. (1985) 'Effect and accuracy in choice', Management Science, Vol. 31, No. 4, pp.395-414.

Katz, J.E., Aakhus, M.A., Kim, H.D. and Turner, M. (2003) 'Cross-cultural comparison of ICTs', in Fortunati, L., Katz, J. and Riccini, R. (Eds.): Mediating the Human Body: Technology, Communication, and Fashion, pp.75-86, Lawrence Erlbaum, Mahwah, NJ.

Kim, B. and Han, I. (2009) 'What drives the adoption of mobile data services? An approach from a value perspective', Journal of Information Technology, Vol. 24, No. 1, pp.35-45.

Kim, H., Chan, H. and Gupta, S. (2007) 'Value-based adoption of mobile internet: an empirical investigation', Decision Support Systems, Vol. 43, No. 1, pp.111-126.

Lee, Y.S., Kim, J.W., Lee, I.S. and Kim, H.Y. (2002) 'Across-cultural study on the value structure of mobile internet usage: comparison between Korea and Japan', Journal of Electronic Commerce Research, Vol. 3, No. 4, pp.227-239.

Mante, E. (2002) 'The Netherlands and the U.S.A. compared', in Katz, J. and Aakhus, M. (Eds.): Perpetual Contact: Mobile Communication, Private talk, Public Performance, pp.110-125, Cambridge University Press, Cambridge, UK.

Marco, V. and Frenkel, T.H. (2000) 'Linking attributes, benefits, and consumer values', Marketing Research, Vol. 12, No. 3, pp.4-10.

Massoud, S. and Gupta, O.K. (2003) 'Consumer perception and attitude toward mobile communication', International Journal of Mobile Communication, Vol. 1, No. 4, pp.390-408.

Orlikowski, W.J. (2000) 'Using technology and constituting structures: a practice lens for studying technology in organizations', Organization Science, Vol. 11, No. 4, pp.404-428.

Payne, J. (1982) 'Contingent decision behavior', Psychological Bulletin, Vol. 92, No. 2, pp.382-402.

Puro, J. (2002) 'Finland: a mobile culture', in Katz, J. and Aakhus, M. (Eds.): Perpetual Contact: Mobile Communication, Private Talk, Public Performance, pp.19-29, Cambridge University Press, Cambridge.

Reynolds, T.J. and Gutman, J. (1988) 'Laddering theory, method, analysis and interpretation', Journal of Advertising Research, Vol. 28, No. 1, pp.11-31.

Richardson, I. (2007) 'Pocket technospaces: the bodily incorporation of mobile media', Continuum, Vol. 21, No. 2, pp.205-215.

Sharma, R.S. and Felix, L.S. (2008) The Worldwide Mobile Data Services Study (WMDSS): 2008 Singapore Survey and Results, SSRN Document dated December 1, 2008 [online] http://ssrn.com/abstract=1329873 (accessed 6 October 2013).

Shi, C.K., Hao, X.M. and Sharma, R.S. (2010) 'A cross market study of mobile data services and devices', Proceedings of the 5th IEEE International Conference on the Management of Innovation and Technology, 2-5 June, Singapore.

Shi, K.C., Hao, X.M. and Sharma, R.S. (2009) 'Why consumers purchase new mobile phones? Modeling the process of decision-making', paper presented at the 8th Global Mobility Roundtable (GMR), 1-3 November, Cairo, Egypt.

Sweeney, J. and Soutar, N. (2001) 'Consumer perceived value: the development of a multiple item scale', Journal of Retailing, Vol. 77, No. 2, pp.203-220. 
Turel, O., Serenko, A. and Bontis, N. (2007) 'User acceptance of wireless short messaging services: deconstructing perceived value', Information and Management, Vol. 44, No. 1, pp.63-73.

Venkatesh, V. and Brown, S.A. (2001) 'A longitudinal investigation of personal computers in homes: adoption determinants and emerging challenges', MIS Quarterly, Vol. 25, No. 1, pp.71-102.

Venkatesh, V. and Davis, F.D. (2000) 'A theoretical extension of the technology acceptance model: four longitudinal field studies', Management Science, Vol. 42, No. 2, pp.186-204.

Vrechopoulos, A., Constantiou, I., Sideris, I. and Doukidis, G. (2003) 'The critical role of consumer behaviour research in mobile commerce', International Journal of Mobile Communications, Vol. 1, No. 3, pp.329-340.

Zeithaml, V.A. (1988) 'Consumer perceptions of price, quality, and value: a means-end model and synthesis of evidence', Journal of Marketing, Vol. 52, No. 3, pp.2-22. 


\section{Appendix}

Table A1 Demographic data for respondents $(\mathrm{N}=3184)$

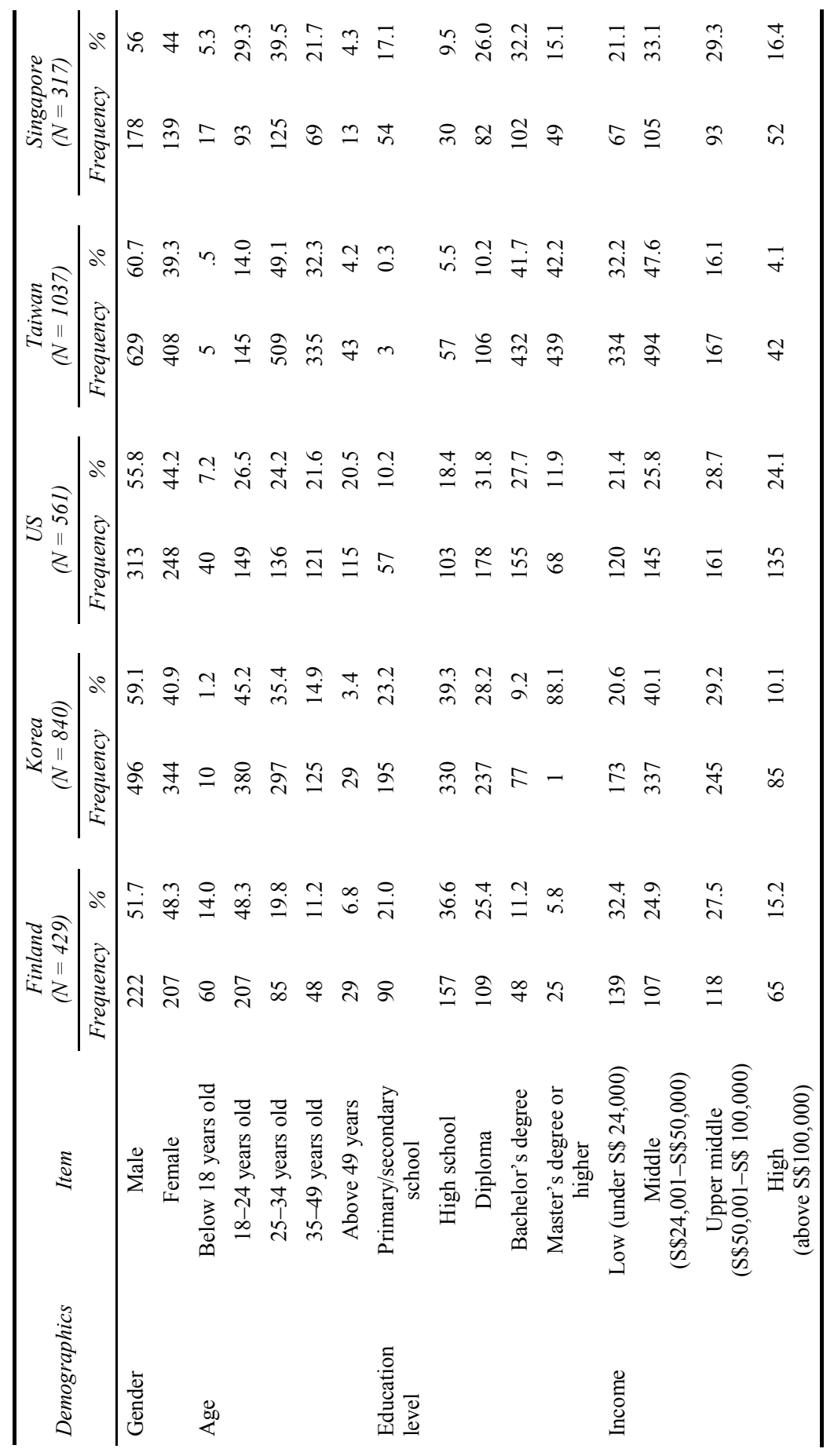


Table A2 Descriptive statistics for constructs

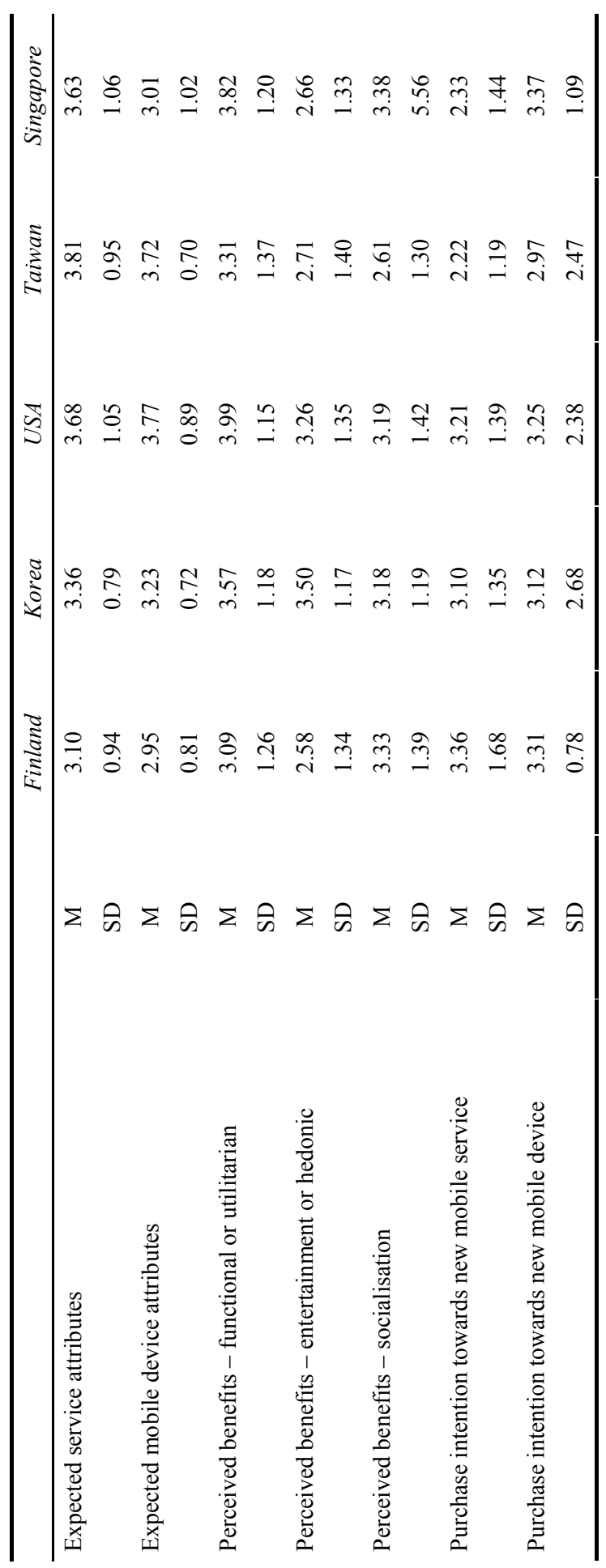


Table A3 Inferential statistics for cause and effect variables $(\mathrm{N}=3,184)$

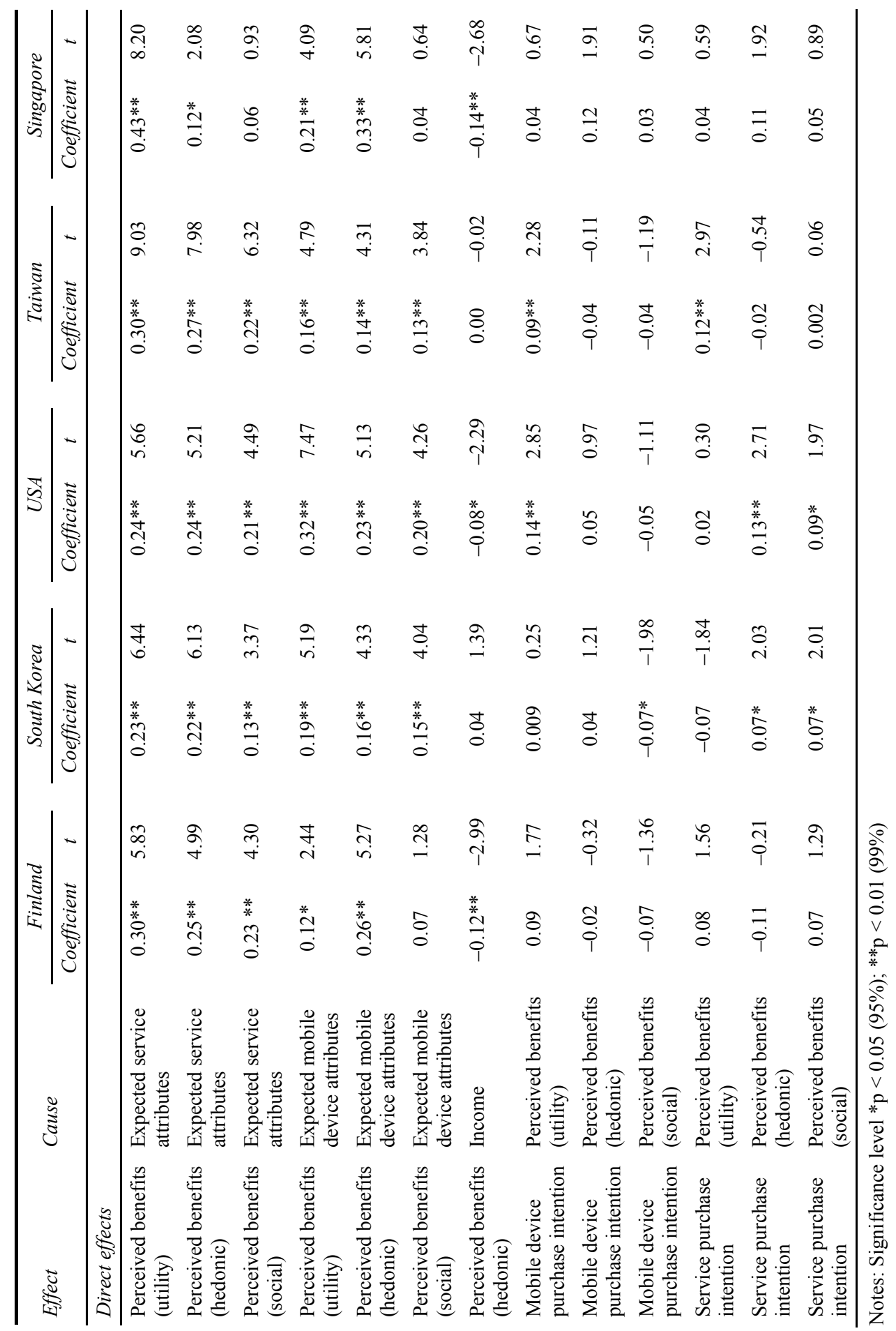


Table A3 Inferential statistics for cause and effect variables $(\mathrm{N}=3,184)$ (continued)

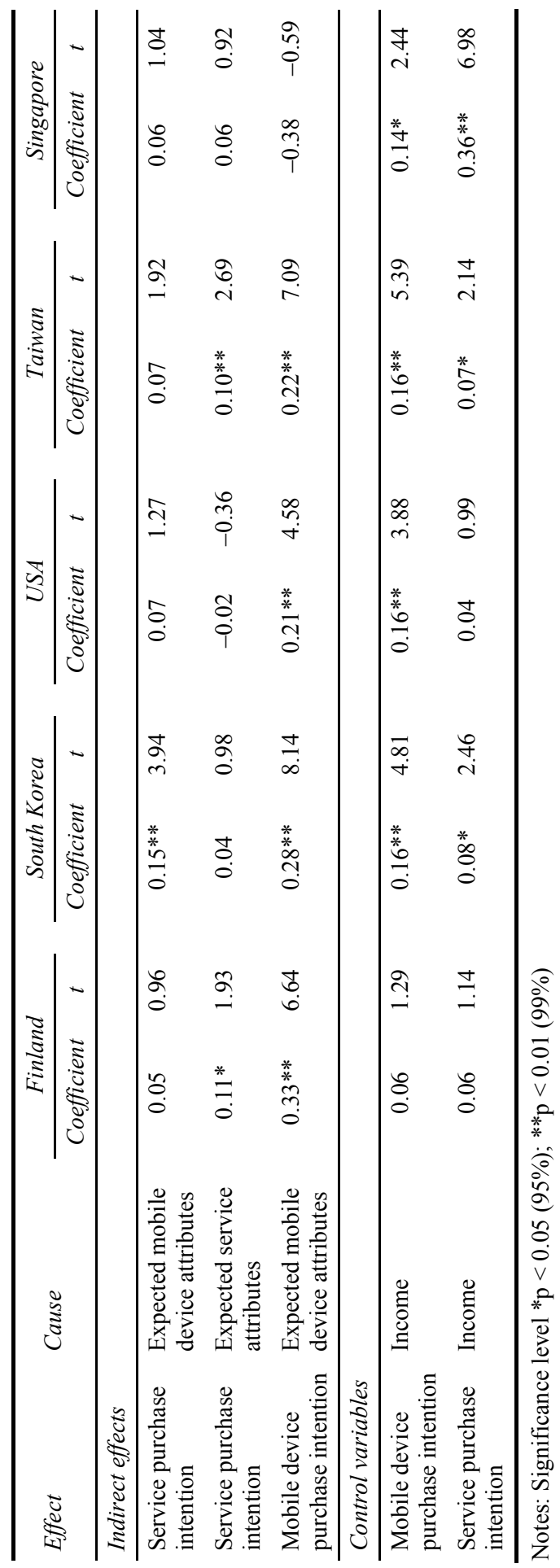

